\title{
Jacketing of existing reinforced concrete structures with composites in view of seismic rehabilitation
}

\author{
Siham Bouras ${ }^{1, a}$, Abdellatif Khamlichi ${ }^{2}$ and Sabri Attajkani ${ }^{2}$ \\ ${ }^{1}$ Department of Physics, Faculty of Sciences at Tetouan, University Abdelmalek Essaadi, Tetouan 93030, Morocco \\ ${ }^{2}$ Department STIC, National School of Applied Sciences at Tetouan, University Abdelmalek Essaadi, Tetouan 93030, Morocco
}

\begin{abstract}
Seismic rehabilitation of pre-code existing buildings requires the choice of the method of strengthening and the determination of the amount of materials to be used optimally. Accurate evaluation of the building response in terms of its capacity at the initial state and that obtained after application of some reinforcement should be performed. For regular buildings, the nonlinear static analysis procedure constitutes a powerful tool that is used to estimate seismic performance. This procedure is characterised by its high effectiveness to account for the non-linear characteristics of the materials involved and provides a direct mean to shape the capacity curve of the construction; enabling then to make the correct decision about rehabilitation task with regards to a desired performance state. In this work, the nonlinear static pushover analysis was performed by means of ZeusNL software. Use was made of the Moroccan seismic regulations RPS2000 version 2011to determine the targeted seismic demand. Considering a four floor reinforced concrete building which is undersized with regards to actual seismic regulation, jacketing with fiber reinforced composites at different reinforcement rates was analyzed. The obtained results were expressed in terms of the lateral resistance capacity and the building tip displacement. Optimal jacketing of columns was then determined.
\end{abstract}

\section{Introduction}

Seismic rehabilitation of existing reinforced concrete (RC) buildings can be performed by using various techniques [1]. Among these, jacketing enables to retrofit building columns by providing external confining stresses which enhance lateral performance. In particular, sheets made from Fiber Reinforced Plastic composites (FRP) can be used as external wrapping bonded on concrete members [2-4].

There are a lot of advantages that are associated to using FRP wraps: high-mechanical properties in terms of tensile strength and elasticity modulus, low unit weight, insensitivity to corrosion, easy for use as confinement jacket and shield against attack of chloride [4-5].

Modelling the constitutive behaviour of FRP confined concrete has been the subject of many investigations [69]. A comprehensive review of models developed to predict the axial stress-strain behaviour of FRP-confined concrete in circular sections can be found in [10]. Empirical models that have been developed to predict the strength of uniformly FRP confined concrete relate failure, for a given plain concrete strength, to the concrete strength increase due to the lateral pressure provided by the FRP. They assume generally a constant value for the confinement effectiveness coefficient. These models have been identified through using experimental results [11]. Modelling actual FRP confined concrete strength may involve complex failure criteria of concrete under triaxial stress [12]. By analyzing 20 existing models to integrate the performance of strength resulting from carbon wraps, Rousakis et al. [13] noticed many divergences.

The majority of these models focused on the monotonic axial behavior of FRP-confined concrete [14] Recently, a unified stress-strain model that enables to represent the axial behavior of circular and square/rectangular RC columns confined internally with transverse steel reinforcements (TSR) and externally with FRP or both TSR and FRP was proposed [15].

This modelling is used in this work where focus is on sizing of jacketing with the aim of realizing seismic rehabilitation of pre-code buildings through the nonlinear static pushover analysis (NSPA) approach.

Considering the Moroccan seismic regulation RPS2000 version 2011 [16], the objective is to size the FRP wrap thickness to apply to columns in order to comply with this code recommendations. A typical regular reinforced concrete building composed of four floors and which is undersized with regards to the RPS2000 seismic regulation is considered. The building response for a given FRP jacketing thickness is calculated by means of the NSPA procedure under ZeusNL software package [17]. The building seismic response is assessed in terms of the lateral resistance capacity and the roof-tip displacement. Optimisation of the FRP wrap thickness is then conducted.

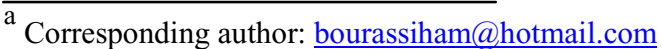




\section{Materials and methods}

\subsection{Empirical modelling of uniform FRP confinement}

The unified stress-strain model proposed in [15] enables to represent the axial behavior of circular and square/rectangular RC columns confined internally with TSR or externally with FRP. The confined strain $\varepsilon_{c c}^{\prime}$ and confined concrete strength $f_{c c}^{\prime}$ are derived according to

$$
\varepsilon_{c c}^{\prime}=\varepsilon_{c}^{\prime}\left[1+35\left(I_{e}^{\prime}\right)^{1.2}\right], \quad f_{c c}^{\prime}=f_{c}^{\prime}\left[1+2.4\left(I_{e}^{\prime}\right)^{0.7}\right]
$$

where $\varepsilon_{c}^{\prime}$ is the axial strain corresponding to concrete cylinder strength, $f_{c}^{\prime}$ is the concrete cylinder compressive strength. The quantity $I_{e}^{\prime}$ is the confinement index at peak stress. It represents the equivalent confinement pressure at peak stress as normalized by the unconfined concrete strength. It is given by

$$
I_{e}^{\prime}= \begin{cases}\min \left\{\frac{\mathrm{v}_{c c}^{\prime}}{\kappa_{1}-\eta} ; \frac{0.15 f_{c}^{\prime}+\kappa_{2} \rho_{s e} f_{h y}}{f_{c}^{\prime}\left(\kappa_{2}-\eta\right)}\right\} & \text { if } \eta<\kappa_{1} \\ \min \left\{\frac{0.15 f_{c}^{\prime}+\kappa_{2} \rho_{s e} f_{h y}}{f_{c}^{\prime}\left(\kappa_{2}-\eta\right)} ; I_{e, \max }^{\prime}\right\} & \text { if } \kappa_{1} \leq \eta<\kappa_{2} \\ I_{e, \text { max }}^{\prime}=\frac{\rho_{s e} f_{h y}+E_{f l} \varepsilon_{f u, a}}{f_{c}^{\prime}} & \text { if } \kappa_{2} \leq \eta\end{cases}
$$

where $E_{f l}$ is the FRP lateral modulus, $f_{h y}$ the yield strength of transverse reinforcement, $\varepsilon_{f u, a}$ the actual ultimate FRP tensile strain. In Equation (2), the quantities $\kappa_{1}, \kappa_{2}, \eta, v_{c c}^{\prime}$ and $\rho_{s e}$ as given in [15] are function of $f_{c}^{\prime}, \varepsilon_{c}^{\prime}, E_{s}, E_{f l}, s, s^{\prime}, c_{x}, c_{y}, A_{s h x}, A_{s h y}$, $\rho_{c c}$ and $w_{i}$, where $E_{s}$ is the modulus of elasticity of transverse reinforcement, $s$ is the TSR spacing, $s^{\prime}$ is the clear TSR spacing, $A_{s h x}$ and $A_{s h y}$ are the total crosssection areas of the transverse reinforcement perpendicular to the $x$ and the $y$ directions, respectively, $c_{x}$ and $c_{y}$ are the widths of the column's core parallel to the $x$ and the $y$ directions, respectively, $w_{i}$ is the clear horizontal spacing between two adjacent laterally supported longitudinal bars, see Figure $1, \rho_{c c}$ is the ratio between the longitudinal reinforcement area and the core section area.

The FRP lateral modulus is given by

$$
E_{f l}=\frac{4 E_{f} K_{f} t}{c_{x}+c_{y}}
$$

where $t$ is the thickness of the FRP and $K_{f}$ the geometric coefficient of confinement effectiveness which is positive and given for a section with vanishing radius of the corners according to ACI 440.2R-08 [18] as function of the column's cross-section dimensions $\ell$ and $h(\ell \leq h)$, the ratio of area of longitudinal steel reinforcement to column's cross-sectional area $\rho_{g}$ and the radius of the corners $r_{c}$.

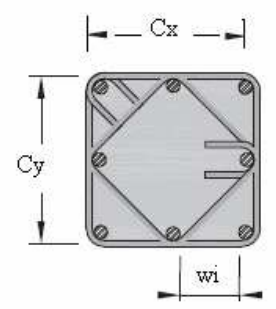

Figure 1. Core cross-section of RC member showing the longitudinal and transversal reinforcements.

In the prepeak zone $\varepsilon_{c} \leq \varepsilon_{c c}^{\prime}$, the stress-strain response of TSR and FRP-confined concrete column is given by

$$
f_{c}=\frac{E_{c t} \varepsilon_{c}}{1+a \varepsilon_{c}+b \varepsilon_{c}^{2}}
$$

The postpeak branch of the stress-strain model after the point $\left(\varepsilon_{c c}^{\prime}, f_{c c}^{\prime}\right)$, for which the concrete gets into the plastic behavior phase and where $\varepsilon_{c c}^{\prime}<\varepsilon_{c} \leq \varepsilon_{c u}$, is given for $f_{c c}^{\prime}<60 M P a$ by

$$
f_{c}=f_{c c}^{\prime} \exp \left[k_{1}\left(\varepsilon_{c}-\varepsilon_{c c}^{\prime}\right)^{k_{2}}\right]+E_{c u}\left(\varepsilon_{c}-\varepsilon_{c c}^{\prime}\right)
$$

The post FRP failure branch $\varepsilon_{c}>\varepsilon_{c u}$ after the point the of FRP rupture $\left(\varepsilon_{c c}^{\prime}, f_{c c}^{\prime}\right)$ is given by

$$
f_{c}=f_{c c, s}^{\prime} \exp \left[k_{1, s}\left(\varepsilon_{c}-\varepsilon_{c c, s}^{\prime}\right)^{k_{2, s}}\right]
$$

In equations (4) to (6), $E_{c t}$ is the tangent elastic modulus of concrete and the quantities $a, b, E_{c u}, f_{c u}$, $\varepsilon_{c u}, k_{1}, k_{2}$ are given in [15] as function of $E_{c t}, f_{c c}^{\prime}$, $\varepsilon_{c c}^{\prime}, E_{f l}, f_{h y}, \rho_{s e}, \varepsilon_{f u}, \varepsilon_{f u, a}, h, c_{x}, c_{y}, w_{i}$. The values of $f_{c c, s}^{\prime}, \varepsilon_{c c, s}^{\prime}, k_{1, s}$ and $k_{2, s}$ are derived using

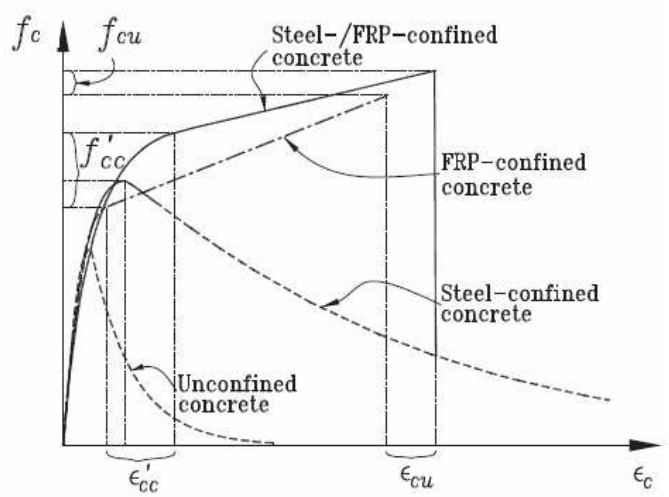

Figure 2. Stress-strain curve for TSR/FRP confined concrete. 
the expressions of $f_{c c}^{\prime}, \varepsilon_{c c}^{\prime}, \quad k_{1}$ and $k_{2}$, respectively, for concrete confined with only transverse steel reinforcement. The module $E_{c u}$ fixes the slope of the curve after the peak.

The stress-strain curve after the point $\left(\varepsilon_{c c}^{\prime}, f_{c c}^{\prime}\right)$ can be of ascending or descending nature depending on the FRP lateral stiffness $E_{f l}$. Figure 2 shows the global stressstrain curve accounting for TSR/FRP confinements.

\subsection{NSPA by means of ZeusNL software}

ZeusNL was developed by Elnashai [11]. This software provides enables to run structural analyses such as conventional and adaptive pushover and nonlinear dynamic time-history. The modelling takes into account both geometric and material nonlinear behaviour. Common concrete and steel material models are available, together with a library of elements for steel and concrete composite section configurations.

In the conventional pushover analysis, the applied loads vary proportionally. The post-peak response is obtained with a displacement based control procedure. Modelling static pushover under ZeusNL software requires entering configuration of members sections, material properties and applied loadings.

As in ZeusNL the stress-strain curve given in Figure 2 is not available, an equivalent nonlinear concrete model (con2) is derived. This model is defined by the ultimate stress $f_{0}^{\prime}$, the ultimate strain $\varepsilon_{c 0}$ and the confinement factor $k$. These are obtained from the Mander [19] model which writes

$$
\frac{f_{c}}{f_{c 0}^{\prime}}=\frac{r\left(f_{c 0}^{\prime}\right) k\left(f_{c 0}^{\prime}\right)\left(\varepsilon_{c 0}^{\prime}\right)^{r\left(f_{c 0}^{\prime}\right)-1}\left[5 k\left(f_{c 0}^{\prime}\right)-4\right]^{r\left(f_{c 0}^{\prime}\right)-1} \varepsilon_{c}}{\left(\varepsilon_{c 0}^{\prime}\right)^{r\left(f_{c 0}^{\prime}\right)}\left[r\left(f_{c 0}^{\prime}\right)-1\right]\left[5 k\left(f_{c 0}^{\prime}\right)-4\right]^{r\left(f_{c 0}^{\prime}\right)}+\varepsilon_{c}^{r\left(f_{c 0}^{\prime}\right)}}
$$

with $\quad r\left(f_{c 0}^{\prime}\right)=\frac{5 \times 10^{6} \varepsilon_{c 0}^{\prime}\left[5 k\left(f_{c 0}^{\prime}\right)-4\right]}{5 \times 10^{6} \varepsilon_{c 0}^{\prime}\left[5 k\left(f_{c 0}^{\prime}\right)-4\right]-k\left(f_{c 0}^{\prime}\right)\left(f_{c 0}^{\prime}\right)^{0.5}} \quad$ and $k\left(f_{c 0}^{\prime}\right)=-1.254+2.254 \sqrt{1+7.94 \varphi\left(f_{c 0}^{\prime}\right)}-2 \varphi\left(f_{c 0}^{\prime}\right)$ in which $\varphi\left(f_{0}^{\prime}\right)$ depends, for a considered direction $x$ or $y$, on $c_{x}, c_{y}, w_{i}, s, s^{\prime}, f_{h y}, \rho_{c c}, A_{s h x}$ and $A_{s h y}$.

For a given member with known TSR and FRP jacketing, the identification of the quantity $f_{0}^{\prime}$ is obtained through assuming $\varepsilon_{c 0}=\varepsilon_{c c}^{\prime}$ and imposing that the Mander stress-strain curve be the closest possible to the actual unified stress-strain model. The optimisation is straightforward since the problem is one dimensional in terms of $f_{0}^{\prime}$. The obtained confinement factor is used to scale up the stress-strain relationship throughout the entire strain range. The tensile resistance is assumed to be $f_{t 0}^{\prime}=6806\left(f_{c 0}^{\prime}\right)^{0.33}$.

\section{Results and discussion}

The building considered is a four-story regular building that lays on a rectangular horizontal surface of
$24 m \times 24 m$. The inter story height is $3 m$. The building behaviour for a given seismic direction can be represented by a four-story three-bay frame with $8 \mathrm{~m}$ bay length. Figure 3 depicts the building elevation.

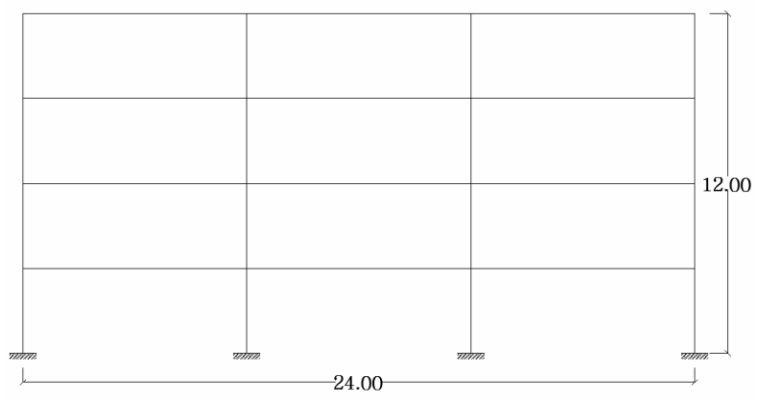

Figure 3. Vertical elevation of the four-storey RC building.

The permanent and variable loads per unit surface are respectively $G=3.3 \mathrm{kN} / \mathrm{m}^{2}$ and $Q=4 \mathrm{kN} / \mathrm{m}^{2}$. The active seismic gravity load is taken to be $P=G+0.2 Q=4.1 \mathrm{kN} / \mathrm{m}^{2}$ [16]. This RC building was designed with concrete resistance $f_{c}^{\prime}=20 M P a$ and steel characteristic resistance $f_{h y}=500 \mathrm{MPa}$. The obtained dimensions of beams are $45 \mathrm{~cm} \times 100 \mathrm{~cm}$ with $3 H A 16$ compressed rebars at the top and $3 H A 20+3 H A 16$ at the bottom. For the columns, the section is $30 \mathrm{~cm} \times 55 \mathrm{~cm}$ with $8 H A 20+10 H A 16$ reinforcement bars. The transverse rebars are $H A 8$ with spacing $s=0.13 \mathrm{~m}$.

The confined concrete behaviour as modelled by Eqs. (1)-(6) depends hugely on the actual FRP wrap thickness. For Carbon Fiber Reinforced Plastics (CFRP) with $E_{f}=70 \mathrm{GPa}, \quad \varepsilon_{f u}=0.89 \%$ and $\varepsilon_{f u, a}=0.85 \%$, Table 1 gives as function of the CFRP thickness the identified Mander parameters. These are obtained through minimizing the difference, in the sense of $L_{1}$ norm, with respect to the unified stress-strain model [15].

Table 1. Parameters that fix the equivalence between the unified model [15] and the Mander model [19].

\begin{tabular}{|c|c|c|c|}
\hline $\begin{array}{c}\text { Thickness } \\
t(\mathrm{~mm})\end{array}$ & $\begin{array}{c}\text { Concrete strength } \\
f_{c 0}^{\prime}(\mathrm{MPa})\end{array}$ & $\begin{array}{c}\text { Concrete } \\
\text { strain } \varepsilon_{c 0}^{\prime} \%\end{array}$ & $\begin{array}{c}\text { Confinement } \\
\text { factor } k\end{array}$ \\
\hline 0.5 & 21.69 & 03411 & 1.179 \\
\hline 1 & 22.91 & 0.3318 & 1.169 \\
\hline 2 & 27.34 & 0.3053 & 1.139 \\
\hline 3 & 37.99 & 0.2682 & 1.098 \\
\hline
\end{tabular}

Figure 4 gives the effect of the CFRP wrap thickness, when applied uniformly to the columns, on the pushover response curve of the reinforced concrete building.

Figure 4 shows that CFRP jacketing is very efficient as it enhances lateral resistance of the building and the capacity of seismic energy dissipation. The amount of CFRP to apply depends on the seismic demand as well as on the actual state of the RC building. 


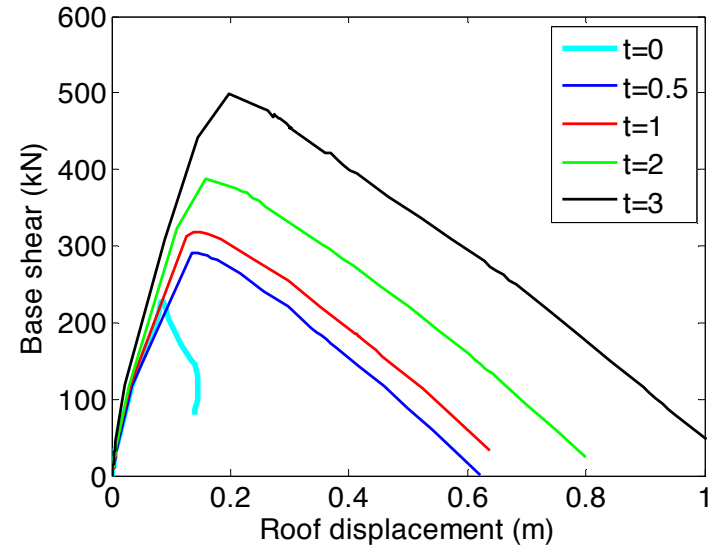

Figure 4. Pushover curve as function of the CFRP wrap thickness $t$ in $\mathrm{mm}$.

The problem is now to retrofit the pre-code building with respect to the limit states of RPS2000 which bounds the building roof displacement ratio and the maximum inter-story drift under the action of the prescribed seismic design load. The limit state associated to roof displacement threshold, $\delta_{\text {roof }}$, should verify

$$
\delta_{\text {roof }} \leq 0.004 H
$$

where $H$ is the total height expressed in $m$.

For the following seismic data associated to zone 4 according to [16]: acceleration $A_{\max }=1.373 \mathrm{~m} / \mathrm{s}^{2}$, velocity $V_{\max }=0.13 \mathrm{~m} / \mathrm{s}$, period $T=0.4836 \mathrm{~s}$, soil foundation of class $S 2$, priority class 2 , ductility coefficient $K=3.5$ and damping coefficient $5 \%$, one obtains amplification factor $D=1.1$, site coefficient $S=1$, priority factor $I=1.2$, velocity parameter $v=0.13$. So, the equivalent static lateral load is

$$
F=\frac{v S D I}{K} W
$$

where $W$ is the total weigh of the building. The lateral loading acting on the equivalent frame is then given by $F=147.52 \mathrm{kN}$.

Given a RFP retrofit as defined by its thickness $t$, the actual roof displacement $\delta_{\text {roof }}$ can be evaluated from a pushover analysis conducted under ZeusNL. Table 2 gives the obtained results

Table 2. Roof displacement as function of the FRP wrap thickness.

\begin{tabular}{|c|c|c|c|c|c|}
\hline $\begin{array}{c}\text { Thickness } \\
t(\mathrm{~mm})\end{array}$ & 0 & 0.5 & 1 & 2 & 3 \\
\hline$\delta_{\text {roof }}(\mathrm{mm})$ & 49 & 52 & 47 & 40 & 33.5 \\
\hline
\end{tabular}

The roof displacement limit as given by equation (8) is: $\delta_{\text {roof , lim }}=48 \mathrm{~mm}$. One can see that by using RFP wrap of thickness $t=1 \mathrm{~mm}$ the roof displacement is verified.

\section{Conclusions}

Considering a regular pre-code reinforced concrete building and the Moroccan seismic regulation RPS2000, the fiber reinforced plastic wrap thickness to apply as jacketing to columns was determined in order to fulfil the roof displacement limit requirement. This was achieved by means of the non-linear static pushover analysis under ZeusNL software package. Equivalent model that considers both transverse reinforcement and composite wrap effect on jacketed column strength was derived according to Mander model.

\section{References}

1. Y.A. Al-Salloum, Composites: Part B 38 (2007)

2. M.W. Li, ACI Struct. J. 91, 4 (1994)

3. O. Ozcan, B. Binici, G. Ozcebe, Eng Struct 32, 4 (2010)

4. G. Campione, Cement \& Concr. Comp. 28 (2006)

5. L. Lam, J.G. Teng, C.H. Cheung, Y. Xiao, Cement \& Concr. Comp. 28 (2006)

6. M. Samaan, A. Mirmiran, M. Shahawy, J. Struct. Eng. 124, 9 (1998)

7. V. Tamuzs, R. Tepfers, E. Sparnins, Mech. Compos. Mater. 42, 2 (2006)

8. T.C. Rousakis, T.D. Rakitzis, A.I. Karabinis, J. Compos. Constr. 16, 6 (2012)

9. H. Baji, H.R. Ronagh, C.Q. Li, Composite Structures 153 (2016)

10. T. Ozbakkaloglu, J.C. Lim, T. Vincent, Eng. Struct. 19 (2013)

11. M.F.M. Fahmy, Z. Wu, (2010), Composites, Part B 41, 3 (2010)

12. T.C. Rousakis, A.I. Karabinis, Mater. Struct. 41, 9 (2008)

13. T.C. Rousakis, T.D. Rakitzis, A.I. Karabinis, J. Compos. Constr. 16 (2012)

14. H.F. Isleema, D. Wang, Z. Wang, Composite Structures 185 (2018)

15. R. Eid, P. Paultre, Engineering Structures 132 (2017)

16. Secrétariat d'État de l'Habitat, Règlement de construction parasismique RPS 2000 (Ministère de l'ATUHE, Royaume du Maroc, 2011)

17. A.S. Elnashai, V. apanikolaou, D. Lee D, ZEUS NL - A system for inelastic analysis of structures (MidAmerica Earthquake Centre, University of Illinois, Urbana, 2003)

18. American Concrete Institute, Guide for the design and construction of externally bonded FRP systems for strengthening concrete structures; ACI 440.2R08 (Farmington Hills, Michigan, 2008)

19. J.B. Mander, M.J.N. Priestley, R. Park, Journal of Structural Engineering 114, 8 (1988) 